\title{
41. Using PERFORM .. WITH TEST AFTER
}

Normally PERFORM .. UNTIL, etc, test the condition for finishing the repetition before starting to carry out the job to be performed.

It is sometimes useful to have the test at the end. This can be done using the WITH TEST AFTER command in the PERFORM statement.

e.g.(1)

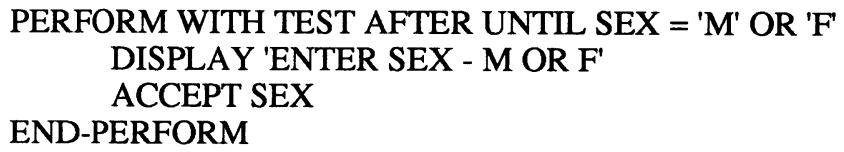

If the user keys in an invalid response by mistake then the routine will be repeated until a suitable letter is typed in.

The WITH TEST AFTER option can also be used when PERFORMing a paragraph.

e.g.(2)

PARA-1.

PERFORM PARA-2 WITH TEST AFTER

UNTIL SEX = 'M' OR 'F'.

$\cdots$

$\cdots$

PARA-2.

DISPLAY 'ENTER SEX - M OR F' ACCEPT SEX.

\section{Exercises}

1. Why might it be advantageous to use the WITH TEST AFTER option in the above examples ? (Consider the alternative).

2. Modify each of the above examples so that either small or large letters are acceptable as the response.

3. a) Write an in-line PERFORM statement which will ask a student to key in a grade - (A, B, C are allowed), then repeat the routine if an invalid letter is typed.

b) Include this routine as a paragraph GET-GRADE in a program which asks 5 students in turn for their name and grade.

4. Write a program which will ask a student for his/her name and mark then check if there are any more students - validating the response to be either ' $\mathrm{Y}$ ' or ' $\mathrm{N}$ ' - and proceeding onto the next student if the answer is ' $\mathrm{Y}$ '. 